\title{
Heart Failing Jehovah Witness Patient Successfully Treated by Minimally-Invasive Left Ventricular Assist Device Implantation without any Blood Transfusions
}

\author{
Andreas Böning ${ }^{1}$ Christof Schmid ${ }^{2}$ \\ ${ }^{1}$ Klinik für Herz-, Kinderherz- und Gefäßchirurgie, UKGM, Standort \\ Giessen, Germany \\ 2 Klinik für Herz-, Thorax- und Herznahe Gefäßchirurgie, \\ Universitätsklinikum Regensburg, Regensburg, Germany
}

Thorac Cardiovasc Surg Rep 2015;4:e1.

What sounds like a headline of a newspaper is the title of a case report regarding cardiac surgery in a high-risk patient, namely, a patient undergoing left ventricular assist device (LVAD) implantation for heart failure treatment. The authors were courageous enough to implant a LVAD in a Jehovah witness, a Christian denomination whose members categorically refuse blood transfusions. They have to be congratulated upon this minimally invasive procedure.

Nowadays, cardiac surgeons usually do not have a problem performing coronary artery bypass graft surgery (off- or onpump, probably with a mini-extracorporeal circulation) without blood transfusion. The same is true for isolated aortic valve replacement.

However, LVAD implantation is a different story: Even if the primary implantation is successful without blood transfusions, the risk with the currently most-used LVADs (Heartmate II, Heartware) is still high that transfusion may be required. Several reports show that gastrointestinal bleeding occurs in 30 to $40 \%$ of LVAD recipients and,
Address for correspondence Prof. Dr. Andreas Böning, Klinik für Herz-, Kinderherz- und Gefäßchirurgie, UKGM, Standort Giessen, Germany (e-mail: andreas.boening@chiru.med.uni-giessen.de).

moreover, the threat of thromboembolism calls for repeated alteration of anticoagulation and transfusion of red blood cells and clotting factors after LVAD implantation. Another major problem is device infection, which can usually only be treated by device replacement. Can this be done without transfusion?

Moreover, at a young age of 48 years it is foreseeable that this patient will suffer severe device complications rendering heart transplantation as the only and final option.

Will the authors do the transplantation as a reoperation with an LVAD without transfusion as well?

Considering these questions, it may not be fair convincing Jehovah witnesses that LVAD implantation can be safely performed without the risks of blood loss andsubsequently-transfusion, and that LVADs assure a better quality of life in the long-term. Finally, in case of bleeding, again the old ethical dilemma for the treating surgeons arises: to give the patient a blood transfusion against his explicit will or to let the patient die.
DOI http://dx.doi.org/ 10.1055/s-0035-1565252. ISSN 2194-7635.
(C) 2016 Georg Thieme Verlag KG Stuttgart · New York 